\title{
Research and Practice of Mixed Teaching Mode Based on MOOC
}

\author{
Taking the National Teacher Education Excellent Resource Sharing Course the Research \\ Methods of Primary Education as an Example
}

\author{
Jichuan Li \\ Linyi University Feixian Campus \\ Linyi, China 273400
}

\begin{abstract}
In order to reform the classroom teaching in colleges and universities, look for the path and countermeasures of the classroom teaching in the Internet + era, based on the construction of the national teacher education quality resource sharing course, the mixed teaching mode is studied and teaching experiments are carried out from the aspects of teaching environment, teacher building and course design changed the single teaching mode dominated by teachers, realized the organic combination of "online" and "offline", mobilized the enthusiasm of students for learning, and innovated teaching methods and learning methods.
\end{abstract}

Keywords-MOOC; mixed teaching; teaching mode; curriculum design

\section{INTRODUCTION}

The exploration and innovation of teaching mode and teaching method has always been the core issue of educational research. How to mobilize students 'interest in learning and correctly handle the relationship between "teaching" and "learning" has become the top priority of the classroom teaching reform in colleges and universities. The Research Method of Primary Education is a compulsory course for primary education in recent years. It is a course designed to train the educational research ability of primary school teachers in the future. Since the beginning of 1999, our school has set up the five-year primary school education specialty, and this course has been offering as a professional compulsory course for junior college student. However, reflecting on the teaching process and teaching effect of more than ten years, there are still some unsatisfactory places. For example, students generally reflect that the theoretical part of the course is difficult to understand, and the operation part is difficult to master; In terms of teaching methods, it also follows the traditional teaching model of teachers-teaching media(teaching materials, multimedia)-students. The form is single and boring, it is not attractive to students, and it cannot mobilize the enthusiasm and initiative of students, and fail to achieve the expected teaching effect.

In 2012, the ministry of education promulgated the Notice on the Construction of State-level Excellent Resources Sharing Courses for Teacher Education, which calls for the establishment of the state-level excellent resources sharing courses for teacher education, in order to implement the educational planning outline and improve the quality of teacher training in an all-round way. Since then, the Ministry of Education has issued a series of documents defining the course of sharing excellent resources of teacher education as a "network-sharing course for social learners, with teachers and students as the main body of service, taking into account the needs of teachers in kindergartens, primary and secondary vocational schools". However, there is no direct experience to draw lessons from how to operate and construct this kind of network sharing course in a specific course. In 2013, Peking University joined Edx Online education platform, Fudan University joined coursera platform, MOOC began to move toward localization in China. Since then, MOOC has become a hot topic in colleges and universities, and the research and practice of MOOC has continued to heat up. In this context, the course team actively concerned about and absorbed the latest research results and ideas of MOOC in the course of curriculum construction, carried out a more comprehensive exploration and innovation of this course, and proposed a mixed teaching model based on MOOC.

\section{RESEARCH VALUE}

\section{A. Theoretical Value}

Based on the teaching practice of colleges and universities, combining with the teaching reform practice of Research Methods of Primary Education, from the perspective of MOOC and Flipping Classroom, explore the teaching mode and strategy suitable for college teaching and student practice, and provide theoretical guidance for the teaching of this course. At the same time, the effect of this teaching mode in the teaching of Research Methods of Primary Education is verified, so as to enrich and develop the theory of flipped classroom, mixed teaching and so on.

\section{B. Practical Value}

- Some people describe MOOC as the "tsunami" of higher education. MOOC brings new strategic thinking and new opportunities to higher education, which will pose a serious challenge to the teaching model of higher education. Therefore, the study of mixed teaching based on MOOC and the discussion of the process of mixed teaching will help us to formulate 
a targeted response plan for training and lay the foundation for training applied talents with innovative consciousness and innovative ability;

- Through the research of MOOC mixed teaching mode and method, it is helpful to promote the renewal of teaching ideas and the improvement of teaching skills of the curriculum group members, and play a leading role in the teaching reform of other disciplines.

- Through the teaching research and experiment of MOOC mixed teaching mode, the organic integration of "online" quality resources and "offline" teacherstudent interaction is realized, mobilizing the enthusiasm of students to participate in class and improving students' interest in learning.

\section{RESEARCH CONTENT}

A. Research on the Mixed Teaching Mode of National Teacher Education Excellent Resource Sharing Course Based on MOOC

The "Mixed teaching mode" is a new teaching model that adapts to "Internet + " based on online "MOOC" and offline "flip classroom". This model of classroom teaching is divided into two parts: First, online learning, students through online resources to learn the teaching content, in order to replace the original classroom teaching; The second is offline learning, that is, classroom learning, which is mainly small class interaction and discussion. Through case analysis and problem discussion, the learned knowledge is consolidated and the ability to analyze problems and solve problems is improved. This research takes the construction of national teacher education excellent resource sharing platform as the research background, and conducts experimental research from five aspects: environmental design, teacher construction, curriculum design, assessment design and guarantee mechanism, and constructs a mixed teaching mode with MOOC as the main body.

\section{B. Research on the Path of Building a Learning Community Based on MOOC Mixed Teaching Mode}

This study takes the learning community as the research object, and explores the path of learning community construction in the context of MOOC from the perspective of the shared vision, learning style and security conditions of the learning community.

\section{Research on the Construction of Course Resources Based on $M O O C$}

The construction of teaching resources is an important part of the construction of the mixed teaching model under the background of MOOC. This research focuses on the design and innovation of resources, knowledge points and ability points, pays attention to the originality and innovation of teaching resources, explores effective ways of teaching resources construction, and improves the utilization rate of teaching resources.

\section{CONSTRUCTION AND PRACTICE OF MiXed TEACHING MODE BASED ON MOOC}

"Mixed teaching mode" is the organic integration of online "MOOC" and offline "flip classroom", that is, students acquire knowledge mainly relying on MOOC network online learning, instead of the original classroom teaching, and the internalization of knowledge, consolidation and ability to enhance in the school classroom, mainly small class interaction and discussion, with a case, and mainly in the discussion of cases, projects, and issues. Taking the construction of the national teacher education excellent resource sharing platform as the research background, it analyzes from the aspects of environmental design, teacher construction and curriculum design, and explores the construction of mixed teaching mode based on MOOC[1].

\section{A. Environmental Design}

The learning environment includes the online learning environment and the classroom learning environment. Through the online learning and classroom environment design, students complete the knowledge internalization process such as pre-class knowledge transfer, class communication, discussion, teacher guidance and homework display. In environmental design, the interpersonal relationship between teachers and student, students and students is an important factor that affects the learning environment.

1) Establish a teaching platform: Establish a mixed teaching model learning platform based on the learning management platform and the love course network platform.

2) Learning community: The MOOC learning community appears in small groups and consists of instructors and learners. In the community, teachers and learners are in the same position, and they are participants. Community members learn from each other, influence each other, negotiate with each other, share resources and experience, and complete learning tasks together. The learning community is usually about 20 people, and a learning group consists of 5-6 people. In this course, each learning community is composed of 20 members, and it is divided into 4 groups. Each group has a group leader, who is responsible for the task communication, question discussion and operations submission. Each group has its own relatively independent research projects (small assignments), and each learning community has relatively comprehensive large projects (large assignments)[2].

\section{B. Teacher Construction}

Teaching staff construction is the key of teaching mode reform in colleges and universities. To be successful, teaching reform must have a team of teachers with a common vision, team spirit, solidarity, cooperation, and initiative. In the mixed teaching model education research and experiment to strengthen team building, first, organize team members to learn MOOC and flip classroom and other modern teaching theories, actively participate in inter-school teaching reform exchange; second, organize team members to study the production of MOOC, familiarize themselves with the use and maintenance of network platform; the third is that the team members should change roles, and change the guidance of the 
traditional classroom teaching to the participants; fourth, the team members should learn to organize and filter the course content, learn to share the learning results with students. These tasks are undoubtedly a big challenge to the construction of the teaching staff. Therefore, the construction of the teaching staff is crucial to the success of teaching reform.

\section{Curriculum Design}

The mixed teaching mode based on MOOC has two advantages compared with the traditional classroom teaching mode. Firstly, network resources play an important role in improving students' interest in learning. Secondly, the advantages of interaction between teachers and students in traditional classroom are fully demonstrated, which can greatly promote the enthusiasm and initiative of teachers and students. In the specific curriculum design, before the class, the teacher should carefully sort out the course content on the basis of clarifying the curriculum construction objectives, determine the key points and difficulties, find out the knowledge points and ability points, and fully consider the students' actual and learning needs, make into micro-courses and other online video, and upload to the online teaching platform to let students learn independently. In class, teachers should be good at guiding students to discover problems from different perspectives, designing problems into different projects or providing cases, dividing them into several groups according to different projects or viewpoints, discussing and drawing conclusions in groups, communicating and sharing among different groups, and dealing with homework and other problems at the same time. Pre-class design requirements are higher in class and classroom design. On the one hand, the core concept must be introduced in micro-classes (teaching videos) within 10-15 minutes of fragmentation. On the other hand, after-school tasks should be enlightening and lead, guide students to read or explore, and support a variety of online interaction.

1) Teaching content: According to the syllabus, we divide the teaching content into ten units, forty-eight hours, of which thirty-two theoretical hours and 16 practical hours. The first part is the general principle of educational research methods, mainly discussing the basic issues of the concept, characteristics, types and development of educational research methods, including a unit; The second part is the procedure of educational research, including three units: topic selection, literature retrieval and research plan formation; The third part is the method of educational research, which includes four units: historical research, investigation research, action research, experimental research; The fourth part is the collation and analysis of educational research materials and the evaluation of educational research achievements, including two units.

2) Teaching objectives and difficulties: According to the relevant requirements of curriculum objectives and syllabus, we have established the teaching objectives from three aspects: knowledge, ability, emotional attitude. The goal of knowledge is to enable learners to understand the general principles of educational research, and to be familiar with the scientific steps and main research methods of educational research;
Ability goal is to help learners master the primary problemsolving ability, so that they can choose the correct research methods and make a reasonable research plan when facing the problems in the field of education, and collate, analyze, express, exchange and evaluate the research materials obtained. Emotional attitude goal, through a large number of case studies, combined with educational practice, in the application of theory to solve practical problems, cultivate students' awareness of scientific research and realistic, serious scientific attitude.

3) Teaching process: The mixed teaching mode based on MOOC makes full use of the advantages of flipped classroom in teaching on the basis of MOOC. The teaching mode of flipping classroom is mainly based on the support of information technology, which effectively links the transmission of pre-class knowledge, the internalization of inclass knowledge and the remediation of after-class knowledge, and creates an autonomous learning environment for students. Based on previous research, we divided this model into three basic links[3].

- Pre-class - knowledge transfer

Pre-class teaching preparation is an important part of classroom teaching. Traditional classroom teaching preparation is mainly to view teaching materials and resources. Students may not be able to understand and master related knowledge, and their knowledge transmission is realized through classroom teaching. In the mixed teaching mode based on MOOC, teachers should determine the teaching objectives according to the curriculum plan and the specific conditions of students, based on knowledge points and ability points, combine the teaching style and teaching experience of teachers, collect teaching materials, and produce teaching videos. Create online teaching resources and upload them to online teaching platform. Due to the fragmentation of video resources and the flexibility of online learning, students can flexibly arrange learning time, learning content and learning progress. Knowledge that is easy or already mastered can be ignored, and knowledge that is difficult or incomprehensible can be read repeatedly until they learn to understand, also can stop to seriously think or take notes. Sort out the problems encountered, and the problems solved can be expressed for everyone to share their views. The unsolvable problems can be solved through the network platform to the teachers and students for help, or be solved in class. This pre-class preparation enables students to master and understand what they have learned and to transfer knowledge before class.

\section{- In-class - knowledge internalization}

In-class is the central part of classroom teaching. The traditional class teaching mode is completed in the classroom because the knowledge transfer is mainly carried out in the class. In the mixed teaching mode based on MOOC, students have realized knowledge transfer before class, and the main purpose of classroom teaching is to create a teaching environment for independent learning. In the specific teaching design, teachers should determine the learning theme, clear the learning task, establish the problem consciousness, and mobilize the enthusiasm of students to explore and solve 
problems. Students study in groups, groups are not fixed, groups are based on different goals and tasks. In group learning, students discuss and communicate according to the topic, task or problem. When they encounter problems, the group solves them together or asks the teacher for help. At the same time, teachers participate in different learning groups to understand the progress of learning, and solve problems in a timely manner. Compared with the traditional teaching mode, this teaching mode optimizes the classroom structure, realizes the transformation from teaching to learning, and improves the efficiency of classroom teaching.

\section{- After-school - Knowledge remediation}

After-class is an extension of classroom teaching and plays the role of knowledge recovery. Teachers sort out the experience and problems found in classroom teaching, and sends the resources generated by these classroom dynamics to students in the form of WeChat and Weibo. Students enjoy it and are easy to accept and spread. At the same time, students who are absent from classes can also use these resources to find and fill gaps. Students who have difficulty learning in the classroom and dare not ask questions can also use this to make remedial learning. The timely remediation of knowledge, so that pre-class, in-class, after-class to achieve a coherent whole, to cultivate excellent students to make up for the poor, make the superior students better and the later students become superior.

\section{CONCLUSION}

Based on the mixed teaching mode of MOOC, with the help of flipping classroom design concept, make full use of the advantages of network resources, which not only improves the utilization rate of network resources, but also avoids the drawbacks of traditional classroom "full-room irrigation" and "inadequate vitality", and increases the classroom capacity. It shows the vigor of classroom teaching, stimulates the enthusiasm and initiative of students, and achieves ideal teaching effect. It provides reference experience for the reform of classroom teaching in colleges and universities[3].

\section{REFERENCES}

[1] Pei Xiaoqin, Xia Chunming, Du Longbing, et al. Preliminary Study on MOOC-based Mixed Teaching Model[ J] . Chemical higher education. 2015(3): 10-13.

[2] Ying Yongxia. Study on the Professional Learning Community of Primary and Secondary School Teachers in the United States [ D] . Southwest University. 2011.

[3] Cao Ying. Analysis of Flip Classroom Teaching Mode in Higher Vocational Colleges Based on Microcourses[ J] . High Teaching Journal. 2015(12): 67-68. 